\title{
Seismic performance and damage evaluation of a reinforced concrete frame with hysteretic dampers through shake-table tests
}

\author{
Amadeo Benavent-Climent \\ Leandro Morillas \\ David Escolano-Margarit
}

Passive energy dissipation devices are increasingly implemented in frame structures to improve their performance under seismic loading. Most guidelines for designing this type of system retain the requirements applicable to frames without dampers, and this hinders taking full advantage of the benefits of implementing dampers. Further, assessing the extent of damage suffered by the frame and by the dampers for different levels of seismic hazard is of paramount importance in the framework of performance-based design. This paper presents an experimental investigation whose objectives are to provide empirical data on the response of reinforced concrete (RC) frames equipped with hysteretic dampers (dynamic response and damage) and to evaluate the need for the frame to form a strong column-weak beam mechanism and dissipate large amounts of plastic strain energy. To this end, shake-table tests were conducted on a $2 / 5$-scale RC frame with hysteretic dampers. The frame was designed only for gravitational loads. The dampers provided lateral strength and stiffness, respectively, three and 12 times greater than those of the frame. The test structure was subjected to a sequence of seismic simulations that represented different levels of seismic hazard. The RC frame showed a performance level of 'immediate occupancy', with maximum rotation demands below $20 \%$ of the ultimate capacity. The dampers dissipated most of the energy input by the earthquake. It is shown that combining hysteretic dampers with flexible reinforced concrete frames leads to structures with improved seismic performance and that requirements of conventional RC frames (without dampers) can be relieved.

\section{INTRODUCTION AND RESEARCH SIGNIFICANCE}

From the mid-1990s, there has been a rapid increase in the implementation of passive energy dissipation devices, EDDs, in structures for improving their performance under seismic loading. The EDDs are special structural elements that when incorporated into a structure absorb or consume a portion of the input energy, thereby reducing energy dissipation demand on primary structural members and minimizing possible structural damage. Reference [1] provides a description of the current practice and recent developments. The move toward more frequent implementations of EDDs in retrofit and new buildings has coincided with the development of guidelines for the analysis and design of structures with this type of device. However, extensive experimental investigations are still needed to provide more reliable analysis and design criteria [2]. Current guidelines consider the EDDs as supplemental elements whose principal function is to reduce the inelastic energy dissipation demands and to limit damaging deformations on the main framing system $[3,4]$. Most of 
these guidelines retain the requirements in place for frames without EDDs in earthquake prone areas. To take full advantage of the benefits of implementing EDDs in structures (two of them being the reduction of weight and cost), it is necessary to further investigate the seismic behavior of these mixed systems, in order to relieve the requirements on the main frame when it is combined with EDDs. In addition, within the framework of performance-based earthquake design, it is of paramount importance to quantitatively assess the extent of damage suffered by the frame and by the EDDs for each level of seismic hazard. Progress in all these aspects calls for laboratory data and experimental evidence. Shake-table tests provide the best source for such information, because they can reproduce the seismic demands on structures subjected to ground motions in a most realistic way, particularly within the nonlinear range, and include cumulative damage effects.

A large number of experimental studies on structures with EDDs have been conducted in the past, either using the EDDs for retrofitting existing frames [5,6] or for new structures [7, 8]. Focusing on shake-table tests conducted on reinforced concrete (RC) frames with EDDs, Pekcan et al. [5] tested a non-ductile frame with elastometic spring dampers and showed that the dampers can reduce the seismic response to a level at which the structural elements can be kept in the elastic range. Shen et al. [6] showed viscous dampers to be very effective in reducing the response of RC frames even in structures with high inherent damping. Lu et al. [7] tested a three-story structure with viscous wall dampers and reported increases of structural damping ratios up to over $20 \%$ and reductions of $30 \%$ to $60 \%$ for displacement response. Hwang et al. [8] tested frames with 'nonstructural' lightly RC exterior/interior walls and upper toggle-brace viscous dampers and demonstrated that the EDDs are effective even when the relative velocity and displacements are limited by the presence of the nonstructural walls.

This paper presents an experimental investigation whose main objectives are to present experimental data from shaking table tests in an RC frame equipped with hysteretic dampers (dynamic response, overstrength, and damage) and to evaluate, for this type of mixed system, the need for the RC frame to form a strong column-weak beam mechanism under lateral loads and the required energy dissipation capacity. Further, the appropriateness of the drift limits proposed by ATC-40 and FEMA-356 in distinguishing between different performance levels is discussed in the context of RC frames with EDDs. It is proven that combining EDDs with conventional RC frames can lead to structures with satisfactory seismic performance as well as economic savings, in terms of both construction costs and repair costs after a severe earthquake. Compared with previous studies, such as the one conducted by Peckan et al. [5] with elastomeric dampers and structures subjected to peak ground accelerations (PGAs) up to $0.4 \mathrm{~g}$, this paper shows that the goal of keeping the main structure basically elastic can also be attained with hysteretic dampers (which are cheaper than elastomeric dampers) and for PGAs as high as $0.54 \mathrm{~g}$. The paper evaluates the damage endured by the EDDs and by the main frame under different levels of seismic hazard by using different damage indexes, such as rotation demand and Park and Ang's index. In this research, an original experimental setup is used for conducting the shake-table tests, and a new particular type of hysteretic damper developed by the authors is employed as EDD.

\section{TEST SPECIMEN}

\subsection{General design considerations and criteria}

The degree to which a certain EDD can accomplish the goal of reducing the inelastic energy dissipation demands and damaging deformations on the main frame depends on the inherent properties of the frame, the properties of the EDD and its connecting elements, the limit state considered and the ground motion characteristics [1]. In this investigation, the EDDs are considered as the main system responsible for satisfying the inelastic energy dissipation demands imposed by the ground motion. Accordingly, the $\mathrm{RC}$ frame is designed only for gravity loads, and detailed requirements now in place for structures without EDDs in seismic zones are relieved. The lateral stiffness of the frame is made relatively high in order to increase its lateral deformation capacity in quasi-elastic conditions. Dissipation of earthquake-induced energy not absorbed by the inherent damping of the structure is directed to the EDDs. The lateral stiffness and strength of the EDDs are determined so that the lateral displacements of the structure do not exceed preestablished values to limit the damage on the main RC frame. As for 
the properties of the EDD, a number of passive energy dissipation devices are either commercially available or under development (viscous fluid dampers, viscoelastic solid dampers, friction dampers, and metallic dampers). In this research, a new low-cost metallic damper developed by the authors called web plastification damper (WPD) [9] is used. The WPDs are installed in the frame in the form of braces, and their energy dissipation capacity relies on yielding the web of short length segments of wide-flange or I-shaped steel sections under out-of-plane bending. Figure 1 shows the WPD after being deformed under axial forces. It is constructed by assembling several short length segments of wide-flange or I-shaped sections, which constitute the energy-dissipating device itself, and two steel bars that remain elastic and function as auxiliary elements (i.e., U-shaped steel). The assemblage is arranged in such a way that when the brace damper is subjected to forced axial deformations, the web of the wide-flange or I-shape section undergoes out-of-plane flexural deformations.

The elements that connect the EDDs with the frame are steel plates arranged in such a way that the installation of dampers does not reduce the clear length of the columns; thus, the original elastic lateral displacement capacity of the bare RC frame is unchanged. As for the limit states considered, the RC frame equipped with EDDs is designed to remain basically elastic ('immediate occupancy' performance level) under a design earthquake expected in the Mediterranean area.

\subsection{Prototype structure}

On the basis of the criteria expounded earlier, a prototype structure consisting of a three-story $3 \times 3$ bay $\mathrm{RC}$ frame, shown in Figure 2, was designed to exclusively support gravity loads with the limit state design method. Ductile reinforcement details and capacity design criteria so that the frame develops a ductile strong column-weak beam plastic mechanism under lateral loads were not used. The dead loads considered were $3.22 \mathrm{kN} / \mathrm{m}^{2}$ in the floors and $2.95 \mathrm{kN} / \mathrm{m}^{2}$ in the roof. The live loads adopted were $2 \mathrm{kN} / \mathrm{m}^{2}$ in the floors and $1 \mathrm{kN} / \mathrm{m}^{2}$ in the roof. The concrete compressive strength assumed in calculations was $25 \mathrm{MPa}$, and the yield strength for reinforced steel was $500 \mathrm{MPa}$. The floor system consisted of one-way joists spaced at $80 \mathrm{~cm}$ apart supported by the main beams (joist-band floor system). In turn, the joists supported a thin concrete slab $6 \mathrm{~cm}$ thick. The cross section of the RC columns measured $30 \times 30 \mathrm{~cm}^{2}$; the section of the main beams that supported the joist was $30 \times 25 \mathrm{~cm}^{2}$ and that of the beams perpendicular to the main beams was $25 \times 25 \mathrm{~cm}^{2}$.

The lateral stiffness ${ }_{s} k_{i}$ and strength ${ }_{s} Q_{y i}$ of the EDDs installed in each story $i$ were determined by applying an energy-based method [10] that involves (i) estimating the lateral strength ${ }_{f} Q_{y i}$ and stiffness $k_{i}$ of the RC frame (without dampers) at each story $i$ through a pushover analysis; (ii) fixing the stiffness ratio $K_{i}={ }_{s} k_{i} / k_{i}$ of each story; (iii) characterizing the ground motion in terms of energy dissipation demand expressed as an equivalent velocity $V_{D, p}$; and (iv) fixing the maximum allowed inter-story drifts $\delta_{m a x, i}$ for a given $V_{D, p}$. In this study, $V_{D, p}=80 \mathrm{~cm} / \mathrm{s}$ was adopted. This $V_{D, p}$ is the value proposed in past studies [11] for regions of moderate seismicity with peak ground acceleration $a_{b}=0.23 \mathrm{~g}$ ( $\mathrm{g}$ is the gravity acceleration) and soft soil conditions, assuming a damping ratio of $5 \%$. The current Spanish seismic code NCSE-02 [12] defines the peak ground acceleration $a_{b}$ as the maximum ground acceleration expected in stiff soil for the design earthquake with 500 years of return period $P_{R}$. NCSE-02 assigns the value $a_{b}=0.23 \mathrm{~g}$ to the city of Granada (southern part of Spain). According to NCSE-02, in the case of soft soil and for a building of ordinary importance, $a_{b}$ must be multiplied by 1.34 to obtain the design ground acceleration. Thus, the design ground acceleration prescribed by the NCSE-02 for the prototype structure is $1.34 a_{b}=0.31 \mathrm{~g}$. The maximum allowed inter-story drifts, $\delta_{\max , i}$, for the $P_{R}=500$ year earthquake were fixed at $1 \%$ of story height, in order to keep the main frame basically elastic. This value of $1 \%$ is the limit proposed by ATC [13] and FEMA [14] to guarantee a performance of the frame within

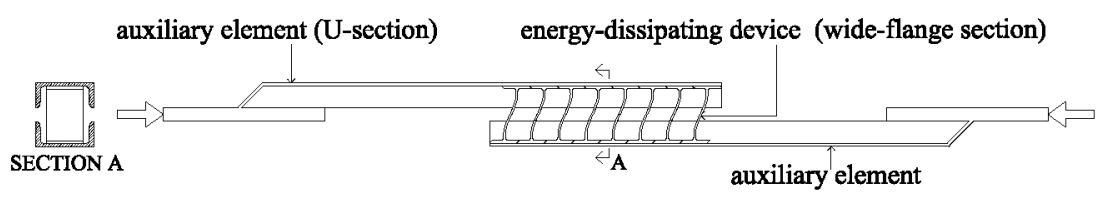

Figure 1. Type of EDD used in the test. 


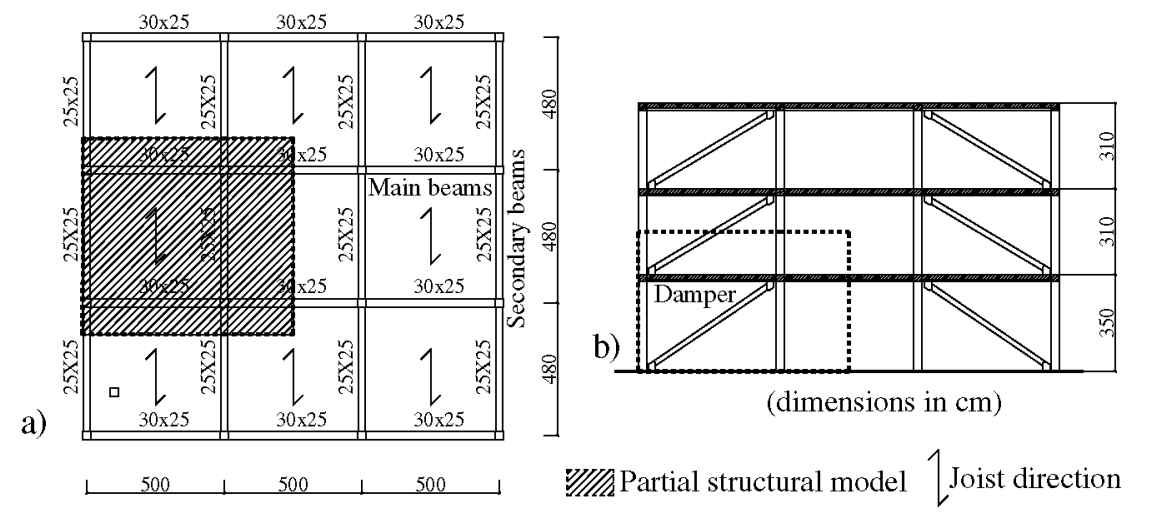

Figure 2. Prototype structure: (a) plan and (b) elevation.

the 'Immediate Occupancy' (IO) level. It is worth emphasizing that in the energy-based method used [10], the designer can choose freely the value of the stiffness ratio $K_{i}$ of each story $i$, but the method enforces that the yield story-drift ratio $v_{i}={ }_{s} \delta_{y i} l_{f} \delta_{y i}$, where ${ }_{s} \delta_{y i}\left(={ }_{s} Q_{y i} / k_{s} k_{i}\right)$ and ${ }_{f} \delta_{y i}\left(={ }_{f} Q_{y i} / k_{j}\right)$, must be less than 1 to guarantee a minimum protection to the main frame. Oviedo et al. [15] recommend using low values of $v_{i}$ because this tends to widen the range of the strength ratio $\beta={ }_{s} Q_{y l} l$ $\left.{ }_{s} Q_{y 1}+{ }_{j} Q_{y l}\right)$ at which the protection of the main frame with the EDDs is maximized and kept almost invariant irrespective of $\beta$. For the prototype building used in this study, a stiffness ratio $K_{i}$ of about 12 was adopted and the energy-based method [10] provided values of ${ }_{s} Q_{y i}$ that correspond to $v_{i}$ of about 0.25 , and values of the strength ratio $\beta={ }_{s} Q_{y i} /\left({ }_{s} Q_{y i}+{ }_{f} Q_{y i}\right)$ of about 0.75 , that is, close to the optimum value proposed by Inoue and Kuwahara [16] for $K_{i}=12$. The resulting required yield displacement of the EDDs was ${ }_{s} \delta_{y i}=2.3 \mathrm{~mm}$, which, expressed in terms of yield story drift, is about $1 / 600$. This yield story drift is not particularly small, and it is commercially available.

\subsection{Design and fabrication of test specimen}

A partial structural model was separated from the prototype by cutting through points of nominal zero bending moment under lateral loads. The partial structural model has the height of the first story and one-half of the height of the second story, and the width of one bay and a half in the direction of the main beams (i.e., those supporting the gravity loading). The test specimen was defined from the partial structural model by applying scale factors of $\lambda_{L}=2 / 5$ for length, $\lambda_{a}=1$ for acceleration, and $\lambda_{\sigma}=1$ for stress. Scale factors for the rest of the physical quantities were set to satisfy similitude requirements. Figure 3(a) shows the geometry and reinforcing details of one of the two identical main frames that formed the test specimen. The two frames were connected by (i) the joists and the thin slab reinforced with a steel mesh and (ii) by perpendicular beams (secondary beams). Coupon tension tests were conducted on samples of reinforcing bars from each batch and size, giving a yield stress of $551 \mathrm{MPa}$ for the longitudinal reinforcement and $636 \mathrm{MPa}$ for the stirrups. Compression tests were conducted on normalized concrete cylinders on the 28th day and on the day of the tests, giving 35 and $40 \mathrm{MPa}$, respectively. The geometry and details of the EDDs are shown in Figure 3(b). Two EDDs of the type shown in the figure were installed in each story. The part of the EDDs undergoing plastic deformations (i.e., the short segments of IPE-140 sections) was made with mild steel S275, whose material properties obtained from standard coupon tension tests were yield stress $f_{y}=340 \mathrm{~N} /$ $\mathrm{mm} 2$, maximum stress $f_{B}=441 \mathrm{~N} / \mathrm{mm} 2$, and Young's modulus $E=2.1 \times 10^{5} \mathrm{~N} / \mathrm{mm} 2$. The connection between the RC frame and dampers was designed so that (i) direct additional stresses in the beamcolumn joint are prevented; (ii) the clear length of the columns is not reduced; and (iii) the region of the beam where the hysteretic damper connects with the RC frame does not fail in shear. The solution adopted is shown in Figure 3(c). The connection between the RC frame and hysteretic dampers was modeled as a pin joint. The geometry and position of the plates was such that the axis of the damper passes through the intersection point of beam and column axes. The region of the beam where each plate is anchored to the RC frame was designed with a shear capacity 1.5 times 
a)
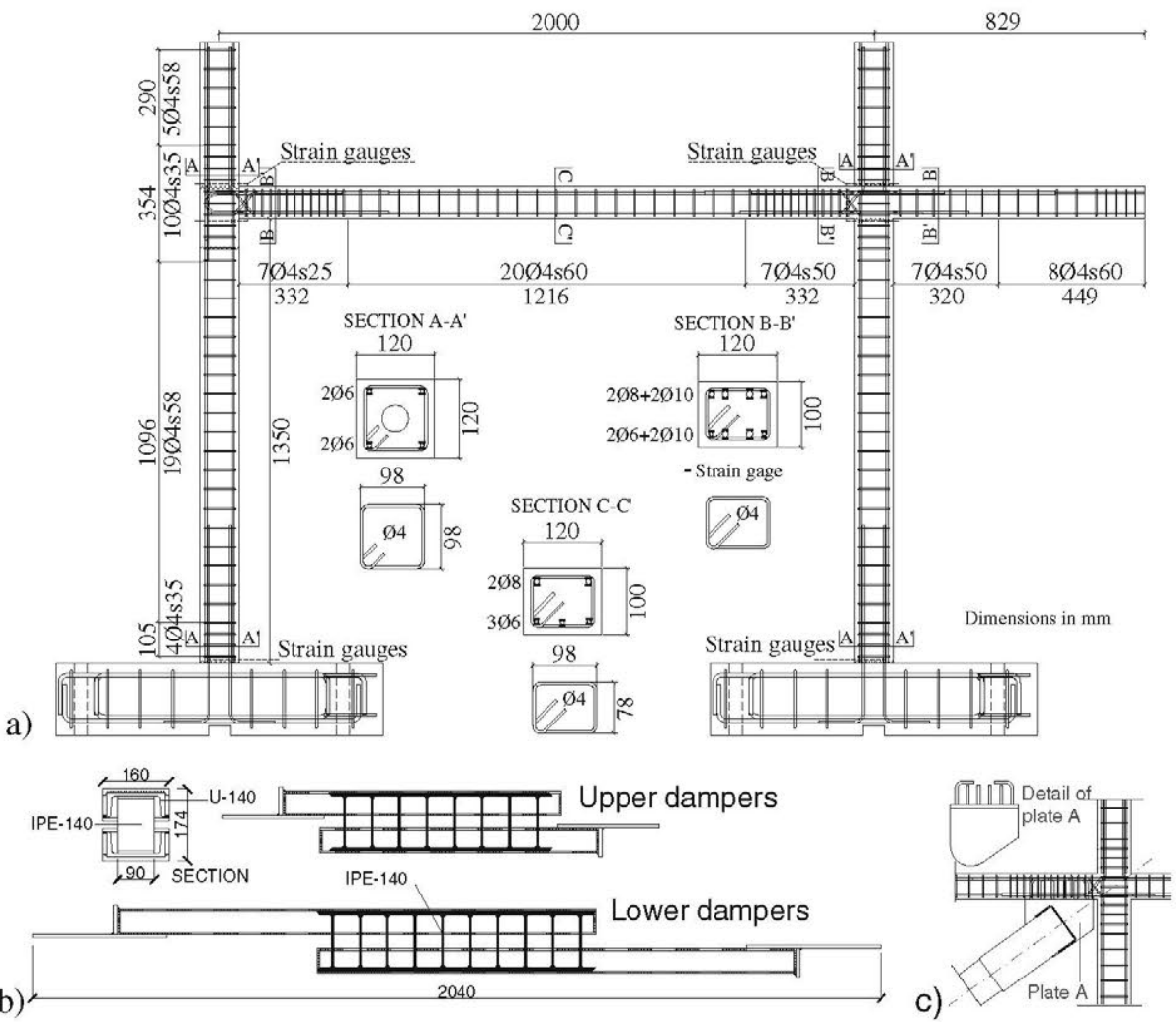

Figure 3. Design of specimen: reinforcement (a), EDDs (b), and connection (c).

larger than the shear force produced by the combined action of the lateral loading, the gravitational forces, and the vertical component of the maximum axial force transferred by the damper. A detail of the connection in the setup is shown in Figure 4(b).

a)

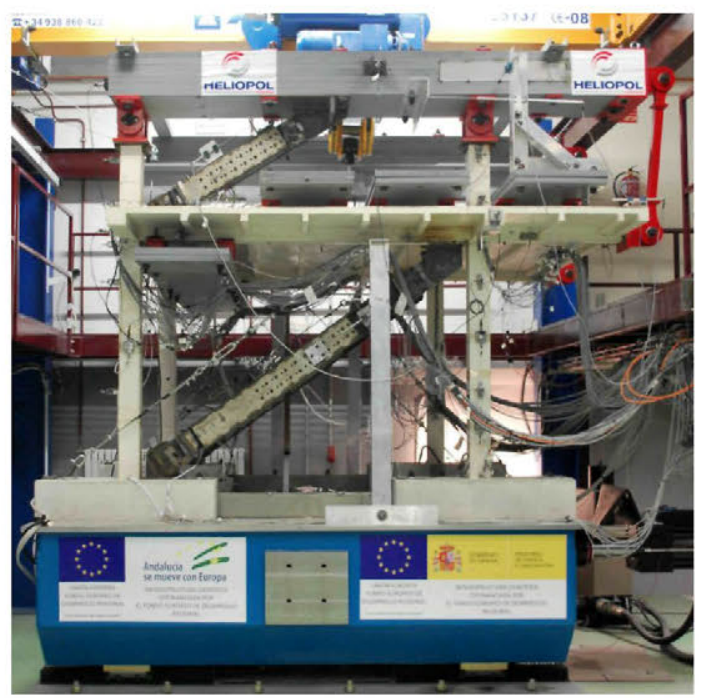

b)

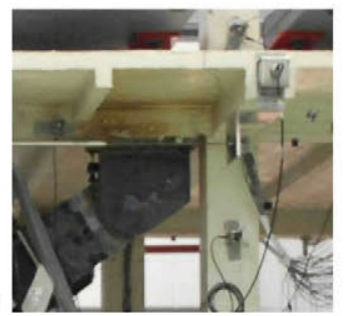

Figure 4. Test setup: (a) general view and (b) connection between RC frame and damper. 


\section{TEST PROGRAM AND INSTRUMENTATION}

\subsection{Test setup}

Figures 4 and 5 show the test setup. The specimen was placed on the uniaxial MTS $3 \times 3 \mathrm{~m}^{2}$ shake-table of the University of Granada, and it was subjected to several uniaxial dynamic tests in the direction of the main beams. Steel blocks were attached at the top of the RC slab and at the top of half columns of the second story (indicated in Figure 5 as 'added weight') to represent the gravity loads acting on the floors and to satisfy similitude requirements between prototype and test model. To reproduce the boundary conditions (i.e., zero bending moment) of the partial structural model when the overall prototype building is subjected to lateral forces, pin joint connections were used at the top of the half columns in the second story and at the ends of the half-beams of the first floor. Vertical movements of the ends of the half-beams of the first floor were prevented by means of pin-ended steel bars that connected the end of the beams with the steel plates (added weight) located on the top of the specimen; these plates have very large flexural stiffness in comparison with that of the RC frame. The total mass of the test specimen (including the additional masses) was $12450 \mathrm{~kg}$. It is worth noting that the purpose of the experiments was to investigate the behavior of the test specimen under earthquake-type dynamic loading, not to reproduce the particular response that the partial structural model would experience inside the overall frame under a particular ground motion, which is influenced by dynamic interactions with the upper part of the structure. The specimen was instrumented with strain gages, uniaxial accelerometers, and displacement transducers (linear variable differential transformers). Strain gages were attached, as shown in Figure 3, at column and beam ends. Data were acquired continuously with a scan frequency of $200 \mathrm{~Hz}$. Five video cameras recorded the experiments, four of them focusing on column bases, beam ends, and beam-column joints.

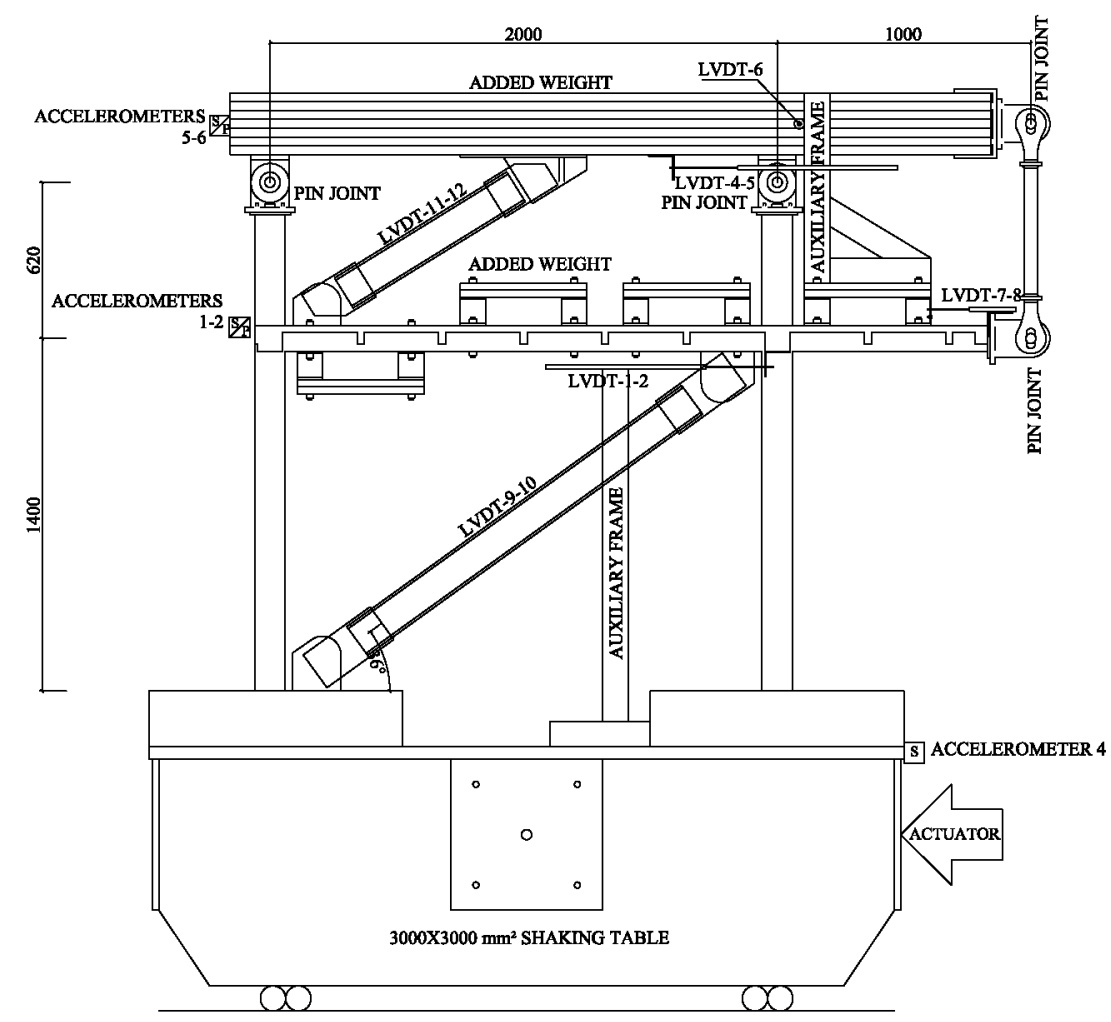

Figure 5. Test setup and instrumentation (dimensions in $\mathrm{mm}$ ). 


\subsection{Seismic simulations}

The specimen was subjected to dynamic tests that consisted of five seismic simulations referred to as $\mathrm{C} 50, \mathrm{C} 100, \mathrm{C} 200, \mathrm{C} 300$, and $\mathrm{C} 350$ herein, in which the shake-table reproduced the ground motion recorded at Calitri during the Campano Lucano (1980) earthquake, scaled in time by the factor $\lambda_{t}=\left(\lambda_{L} / \lambda_{d}\right)^{0.5}=0.63$, and in amplitude, respectively, to $50 \%, 100 \%, 200 \%, 300 \%$, and $350 \%$. The corresponding peak ground accelerations $P G A$ were $0.08,0.16,0.31,0.47$, and $0.54 \mathrm{~g}$, respectively. This seismic ground acceleration record was selected because in the range of periods of interest the response spectrum is close to that prescribed by the Spanish seismic code for Granada. Figure 6 shows the normalized response spectrum $S_{a} / P G A$ of the (unscaled) Calitri record, and the design spectrum prescribed by the Spanish code. Also shown are the (unscaled) fundamental period $T_{1}$ and the period corresponding to the effective stiffness at the maximum displacement amplitude $T_{\text {eff. }}$. In the period range of interest, the $S_{a} / P G A$ of Calitri spectrum varies between 1.87 and 2.86 , with a mean value of 2.24 that is close to the $S_{a} / P G A$ prescribed by the spectrum of the Spanish code (2.5). Each $P G A$ represents a different seismic hazard level (SHL) at the site (Granada), referred to hereafter as SHL-1, SHL-2, SHL-3, SHL-4, and SHL-5. SHL-1 represents a 'very frequent' earthquake, SHL-2 a 'frequent' earthquake, SHL-3 a 'rare' earthquake, and SHL-4 and SHL-5 'very rare' earthquakes. The SHLs can, respectively, be associated with $P_{R}$ of 17, 97, 500, 1435, and 2032 years. For relating $P_{R}$ with $P G A$, the following expression proposed by code NCSE-02 [12] was used: $a_{b, P R}=a_{b}\left(P_{R} / 500\right)^{0.4}$, where $a_{b, P R}$ is the peak ground acceleration for a given $P_{R}$. Before and after each simulation, free vibration tests were conducted to determine the period $T_{1}$ and damping fraction $\xi$ of the first vibration mode. It is worth noting that the PGA of seismic simulation C200 coincides with the design ground acceleration $(0.31 \mathrm{~g})$ used for designing the prototype structure.

\section{TEST RESULTS AND INTERPRETATION}

\subsection{Dynamic characterization}

Table I summarizes the overall response of the test specimen in each seismic simulation. The third and fourth columns of Table I show the fundamental period $T_{1}$, and the damping ratio $\xi$ obtained from the free vibration tests conducted before each seismic simulation. $T_{I}$ was calculated by averaging the time between response peaks for several cycles and dividing by the number of cycles; $\xi$ was determined using the logarithmic decrement method. It is observed that both $T_{1}$ and $\xi$ remained basically unchanged, reflecting an undamaged structure that kept its initial lateral stiffness and inherent damping. The occurrence of plastic deformations on the RC frame typically causes important increases of both $T_{1}$ and $\xi$, but this effect was not observed in the tested specimen.

\subsection{Overall response}

The beams and columns of the test specimen were modeled as shown in Figure 7 for convenience in the forthcoming discussions. Beams and columns of each of the two frames are idealized with macro models consisting of linear elastic members connecting two plastic hinges at the ends that concentrate the inelastic flexural deformations. The software used was IDARC version 7.0, developed at the University

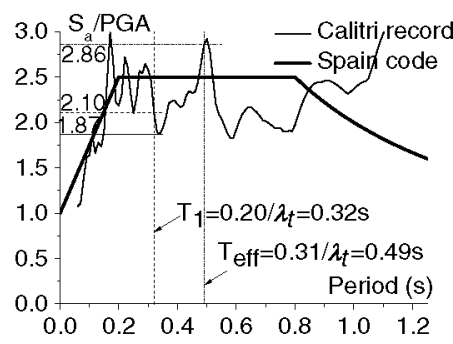

Figure 6. Comparison of spectra. 
Table I. Overall response.

\begin{tabular}{|c|c|c|c|c|c|c|c|c|c|c|c|c|}
\hline \multirow[b]{3}{*}{ Test } & \multirow[b]{2}{*}{ SHL } & \multirow[b]{2}{*}{$\mathrm{T}_{1}$} & \multirow[b]{2}{*}{$\xi$} & \multicolumn{3}{|c|}{ Story 1 (lower) } & \multicolumn{3}{|c|}{ Story 2 (upper) } & \multicolumn{2}{|c|}{ Top } & \multirow[b]{2}{*}{ SPL } \\
\hline & & & & $u_{\text {max }}^{t}$ & ID & $\mathrm{ID}_{\mathrm{r}}$ & $\ddot{u}_{\max }^{t}$ & ID & $\mathrm{ID}_{\mathrm{r}}$ & ID & $\mathrm{ID}_{\mathrm{r}}$ & \\
\hline & & $\mathrm{s}$ & $\%$ & $\mathrm{~g}$ & $\%$ & $\%$ & $\mathrm{~g}$ & $\%$ & $\%$ & $\%$ & $\%$ & \\
\hline c50 & SHL-1 & 0.20 & 2.6 & 0.13 & 0.14 & 0.00 & 0.31 & 0.16 & 0.00 & 0.15 & 0.00 & IO \\
\hline c100 & SHL-2 & 0.20 & 2.6 & 0.27 & 0.29 & 0.01 & 0.56 & 0.33 & 0.00 & 0.30 & 0.01 & IO \\
\hline c200 & SHL-3 & 0.21 & 2.6 & 0.52 & 0.64 & 0.03 & 0.83 & 0.58 & 0.00 & 0.60 & 0.03 & IO \\
\hline c 300 & SHL-4 & 0.21 & 2.6 & 0.71 & 1.07 & 0.07 & 1.10 & 0.96 & 0.03 & 1.03 & 0.10 & IO \\
\hline c350 & SHL-5 & 0.21 & 2.6 & 0.81 & 1.43 & 0.10 & 1.10 & 1.10 & 0.00 & 1.31 & 0.10 & IO \\
\hline
\end{tabular}
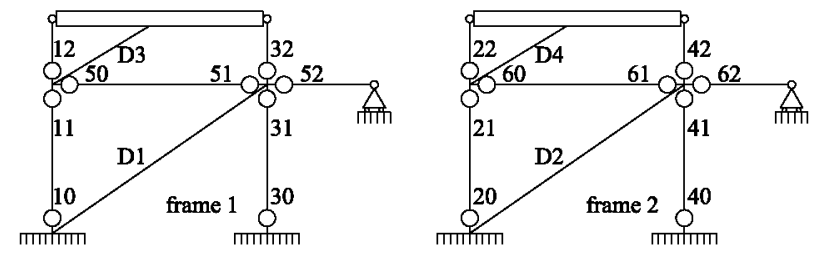

Figure 7. Structural model with plastic hinges and dampers identified.

at Buffalo - the State University of New York (New York, USA) [17]. With this program, the plastic hinges are modeled as nonlinear rotational springs whose moment-rotation relationship, $M-\varphi$, under cyclic loads (hysteretic behavior) is governed by the moment-curvature $M$ - $\varphi$ curve under monotonic loading (skeleton curve), and four parameters (HC, HBD, HBE, and HS) that control the stiffness degradation, the strength degradation and pinching effects. The $M-\varphi$ curve under monotonic loading was calculated with fiber models. Values of parameters HC, HBD, HBE, and HS corresponding to moderate strength and stiffness degradation and moderate pinching were selected $(\mathrm{HC}=10$, $\mathrm{HBD}=0.3, \mathrm{HBE}=0.15$, and $\mathrm{HS}=0.25$ ). Each plastic hinge is labeled with an identification number $k$. Figure 7 also indicates the position of the EDDs, labeled as D1, D2, D3, and D4. The structural model shown in Figure 7, with the member sections and material properties described in section 2.3 but without the EDDs, was subjected to a nonlinear static pushover analysis in order to estimate, for each story $i$, the nominal lateral strength of the bare frame, giving ${ }_{f} Q_{y 1}=17.6 \mathrm{kN}$ for the first (lower) story and ${ }_{f} Q_{y 2}=15.3 \mathrm{kN}$ for the second (upper). These nominal lateral strengths correspond to the formation of the first plastic hinge (i.e., to first reach the flexural resistance) in any member of the frame. The nominal lateral strength at the onset of yielding of the EDDs were calculated with the equations of reference [9], giving ${ }_{s} Q_{y 1}=54.5 \mathrm{kN}$ and ${ }_{s} Q_{y 2}=45.7 \mathrm{kN}$ for the first and second stories, respectively. The lateral inter-story drifts at the onset of yielding of the EDDs were also calculated with the equations of reference [9], and they were much smaller (about one-fourth) than those of the (bare) frame. The nominal base shear force of the frame with EDDs corresponding to the formation of the first plastic hinge in the frame can be estimated as $\left({ }_{f} Q_{y 1}+{ }_{s} Q_{y 1}\right)$. The corresponding base shear force coefficient $\alpha_{B}$, ${ }_{n o m}$ is $\alpha_{B, n o m}=\left({ }_{f} Q_{y 1}+{ }_{s} Q_{y 1}\right) / W=(17.6+54.5) / 122=0.59$, where $W=122 \mathrm{kN}$ is the total weight.

For addressing the dynamic response, the structural model shown in Figure 7 was further idealized with a lumped-mass system with masses $m_{1}$ and $m_{2}$. The first one, $m_{1}=6480 \mathrm{~kg}$, represents the mass of the floor diaphragm with the added weight; the second one, $m_{2}=5970 \mathrm{~kg}$, represents the added weight put on top of the columns. Each concentrated mass was assigned with a degree of freedom (horizontal translation in the direction of shaking). The dynamic equilibrium of the specimen is governed by

$$
\mathbf{m} \ddot{\mathbf{u}}^{t}+\mathbf{c} \dot{\mathbf{u}}+\mathbf{F}_{\mathrm{s}}=\mathbf{0}
$$

where $\mathbf{m}$ is the diagonal mass matrix, $\ddot{\mathbf{u}}^{t}$ is the vector of absolute accelerations, $\mathbf{c}$ is the damping matrix, $\dot{\mathbf{u}}$ is the vector of relative velocities, and $\mathbf{F}_{\mathbf{S}}$ the vector of restoring forces exerted by the structure. Because $\mathbf{m}$ is known and $\ddot{\mathbf{u}}^{t}$ was measured with the accelerometers, the total shear force $F_{I, B}$ exerted 
by the inertial forces $\mathbf{F}_{\mathbf{I}}=\mathbf{m} \ddot{\mathbf{i}}^{t}=-\left(\mathbf{c} \dot{\mathbf{u}}+\mathbf{F}_{\mathbf{S}}\right)$ at the base of the structure can be readily calculated as $F_{I, B}=\mathbf{F}_{\mathbf{I}}^{\mathbf{T}} \mathbf{1}$, where $\mathbf{1}$ is the unit vector. $F_{I, B}$ is plotted in Figure 8 against the displacement of the top of the structure $\delta_{T}$, for each seismic simulation. The figure reflects a stable energy dissipation behavior with minor pinching in the loops. In the instants of zero velocity (i.e., $\dot{\mathbf{u}}=\mathbf{0}$ ), the damping forces $\mathbf{c} \dot{\mathbf{u}}$ are null, and $F_{I, B}$ coincides with the base shear force carried by the structure $Q_{B}$. Values of $F_{I, B}$ when $\dot{\mathbf{u}}=\mathbf{0}$ and thus $F_{I, B}=Q_{B}$ were calculated for each seismic simulation and are plotted with solid symbols in Figure 8. The bilinear envelope of these points is drawn with bold lines in the figure, and it can be interpreted as the 'capacity curve' of the structure. From this capacity curve, a yield base shear force, $Q_{B y}$, and a yield top displacement $\delta_{T}$ are defined for each domain of loading, giving $Q_{B y}{ }^{+}=123.6 \mathrm{kN}, \delta_{T y}{ }^{+}=11.2 \mathrm{~mm}, Q_{B y}{ }^{-}=108.8 \mathrm{kN}$, and $\delta_{T y}{ }^{-}=10.1 \mathrm{~mm}$. This capacity curve allows us to calculate the average base shear force coefficient, $\alpha_{B}=0.5(123.6+108.8) / 122=0.95$. Comparing $\alpha_{B}=0.95$ with the nominal base shear force coefficient $\alpha_{B, n o m}=0.59$ estimated earlier, it is concluded that the structure has an overstrength of $0.95 / 0.59=1.61$, which is $24 \%$ larger than that specified by Eurocode 8 [18] for multistory, multi-bay frames or frame-equivalent dual structures (1.3). It is worth noting, however, that the overstrength ratio of Eurocode 8 and the one estimated in this study are not directly comparable. The former is obtained with the peak force level of a capacity curve derived numerically from a static nonlinear pushover analysis, while the later is estimated with an 'experimental' capacity curve obtained from dynamic shake-table (cyclic) tests.

The overall response of the specimen is summarized in Tables I and II. For each seismic simulation, Table I shows in columns five to 10 the maximum response acceleration $\ddot{u}_{\max }^{t}$, the maximum interstory drift $\mathrm{ID}$, and the residual inter-story drift $\mathrm{ID}_{\mathrm{r}}$ of each story. Columns 11 and 12 show the maximum inter-story drift $\mathrm{ID}$ and the residual inter-story drift $\mathrm{ID}_{\mathrm{r}}$ at the top of the specimen.
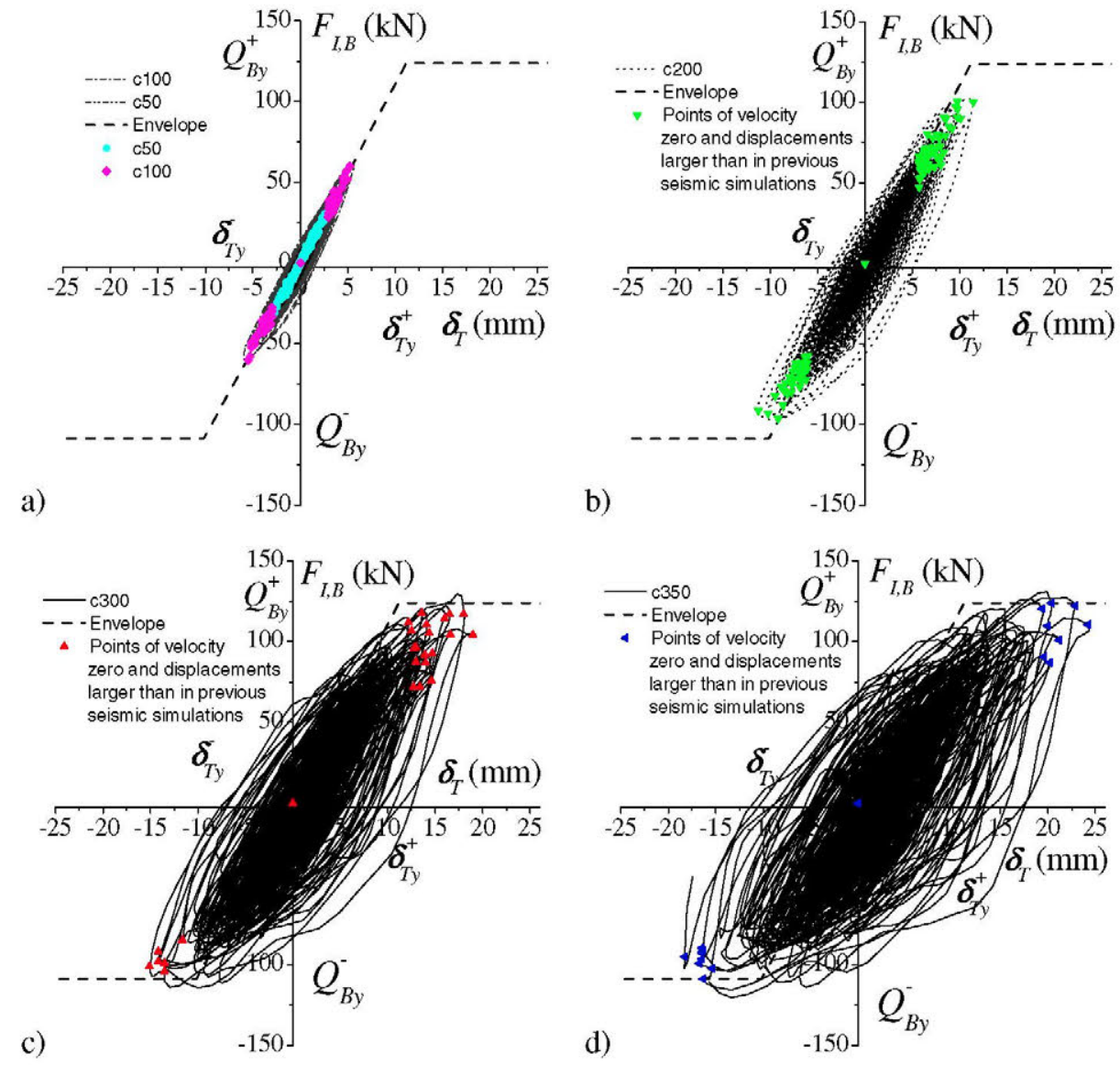

Figure 8. Base shear force versus top displacement $\delta_{T}$, with points with zero damping forces (open circles), for seismic simulation: (a) c50 and c100, (b) c200, (c) c300, and (d) c350. 


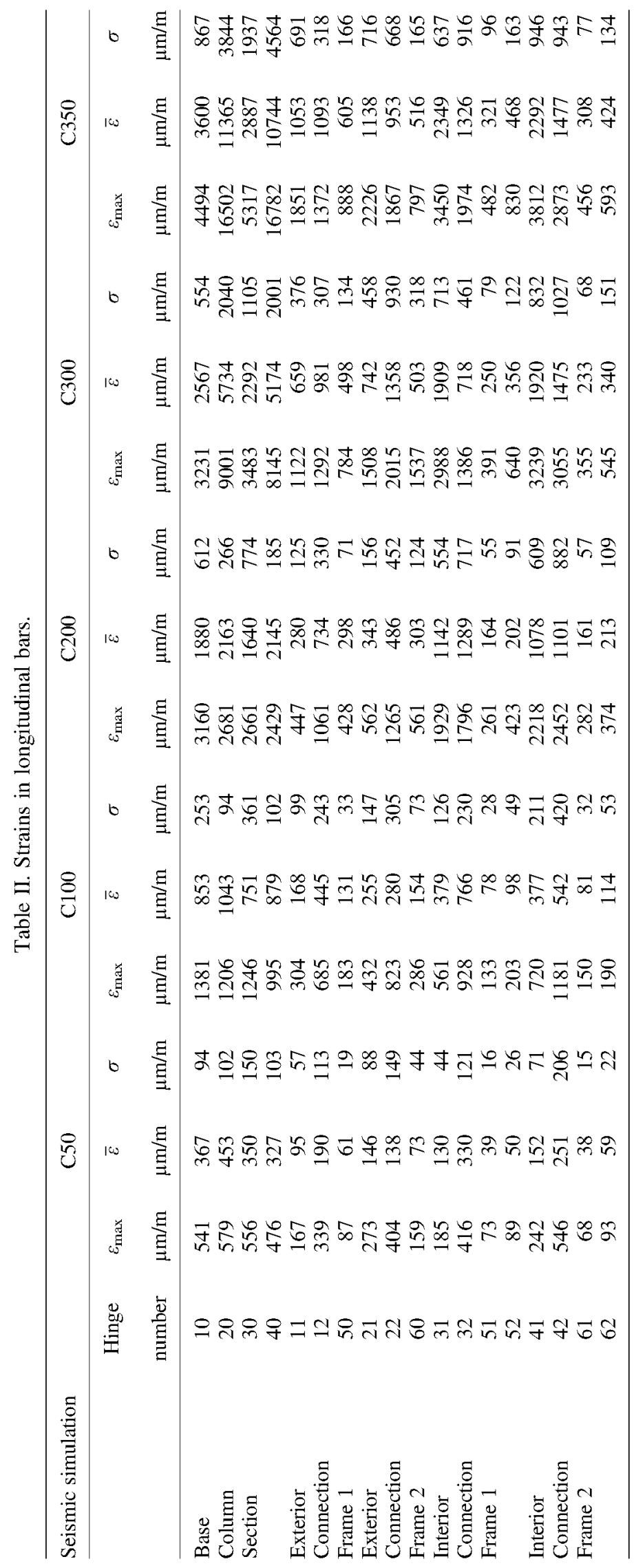


Table II summarizes the maximum strains measured in the longitudinal bars located at the member end sections of the two RC frames. Each member end section is a potential plastic hinge under lateral loadings, and it is identified with the number shown in Figure 7. In Table II, the member end sections are grouped according to their position in the frames as base, interior beam-column connection and exterior beam-column connection. Several longitudinal reinforcing bars were instrumented at each member end section as shown in Figures 2 and 3. Table II shows the maximum $\varepsilon_{\max }$, the average $\bar{\varepsilon}$, and the standard deviation $\sigma$ of the strains measured at each section. The yield strain of the steel $\varepsilon_{y}$ was $2625 \mu \mathrm{m} / \mathrm{m}$.

From the information shown in Tables I and II, it follows that the overall response of the RC frame was basically elastic, with light or very light damage, even for the severest seismic simulation C350. Plastic hinges developed only at the base of the columns of the first story, but the strains averaged at each column base section $\bar{\varepsilon}$ did not exceed $4.5 \varepsilon_{y}$, which is a relatively small value. In the rest of the RC frame, the average strains at member end sections $\bar{\varepsilon}$ remained clearly below $\varepsilon_{y}$, ranging from $0.4 \varepsilon_{y}$ to $0.9 \varepsilon_{y}$ in columns, and from $0.16 \varepsilon_{y}$ to $0.23 \varepsilon_{y}$ in beams. The widths of the concrete cracks at the potential plastic hinges numbered in Figure 7 were also measured after each seismic simulation. The crack width remained between 0.08 and $0.1 \mathrm{~mm}$, except in the plastic hinge labeled as number 12 in Figure 7, where the crack width was $0.2 \mathrm{~mm}$. Based on the measurements of strains in longitudinal steel rebars, the observed width of the concrete cracks, the fact that residual inter-story drifts $I D_{r}$ were negligible $\left(I D_{r} \leqslant 0.1 \%\right)$ and $T_{1}$ and $\xi_{1}$ remained basically unchanged (Table I), the structural performance level of the $\mathrm{RC}$ frame can be classified as ' $\mathrm{IO}$ ', even though the maximum inter-story drifts $I D$ for seismic simulations $\mathrm{C} 300$ and C350 were above the $1 \%$ limit established by ATC-40 [13] and FEMA-356 [14].

In contrast to the RC frame, the EDDs underwent plastic deformations during the tests, especially those located in the lower story. Figures 9, 10 and 11 show the axial force $N$ versus axial displacement $\Delta$ of each EDD measured during seismic simulations C200, C300, and C350. The $N-\Delta$ curves for seismic simulations C50 and C100, which represent a low SHL for the building site, are not included because the EDDs remained elastic. During seismic simulation C200, which represents a strong ground motion (the design earthquake) at the building site, the EDDs of the upper story remained elastic, and those of the lower story exhibited minor excursions in the nonlinear range. During seismic simulations C300 and C350, representing very rare earthquakes at the site, the EDDs of the upper story suffered minor plastic excursions, while those of the lower story underwent a large number of cycles of plastic deformations that resulted in very severe damage at the end of
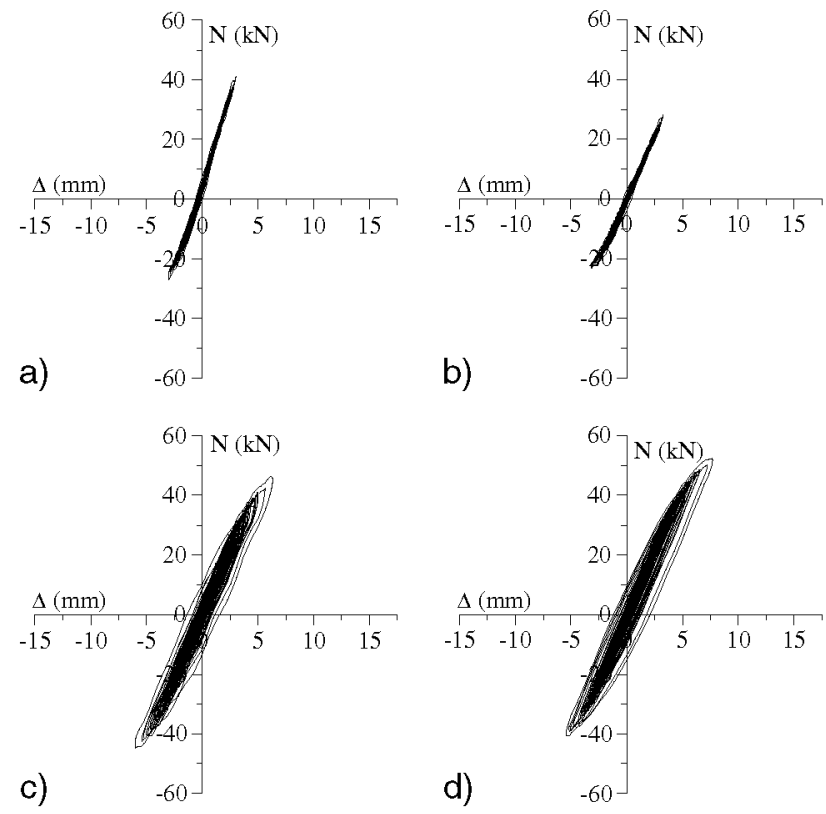

Figure 9. Response for C200 of EDDs: (a)D3, (b)D4, (c)D1, and (d) D2. 

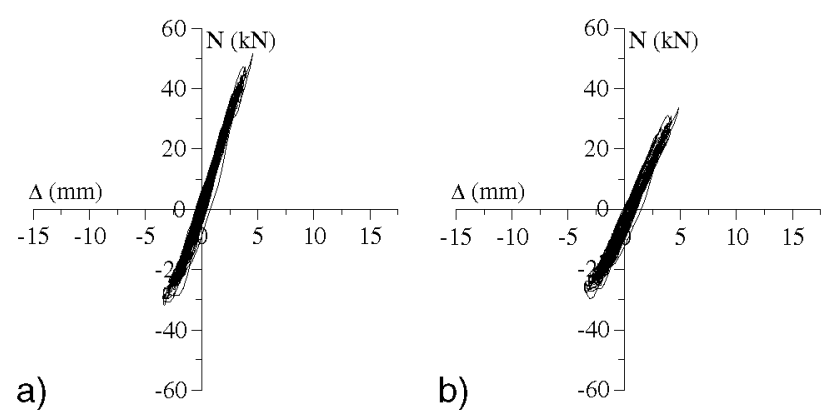

C)
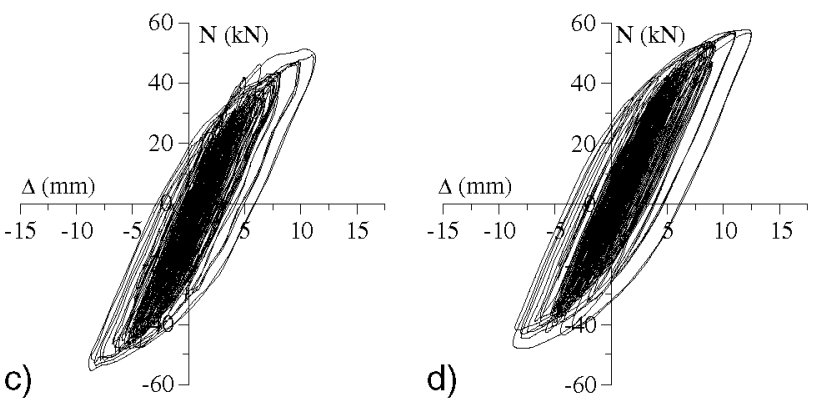

Figure 10. Response for C300 of EDDs: (a) D3, (b) D4, (c) D1, and (d) D2.
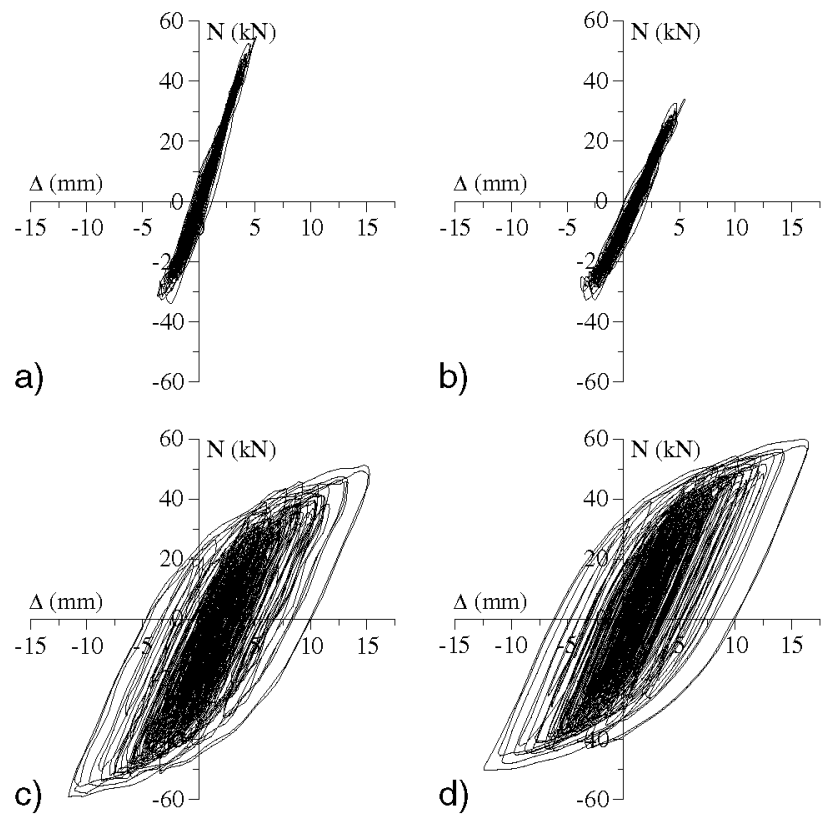

Figure 11. Response for C350 of EDDs: (a)D3, (b)D4, (c)D1, and (d)D2.

simulation C350. The next section presents a quantitative evaluation of the (light) damage suffered by the RC frame and of the (severe) damage to the EDDs. In the case of a less flexible RC frame, the overall response described earlier would change depending on whether the fundamental period of the RC frame falls in the short, long, or in the vicinity of the corner period between the short and long period ranges of the energy input spectrum of the ground motion. The authors believe that similar results would be obtained with a less flexible RC frame if the variation of the response period of the structure does not imply a significant variation in the amount of energy input by the earthquake, and if the $\mathrm{RC}$ frame remains essentially elastic while the dampers respond inelastically. 


\subsection{Damage at global level}

Equation (2) establishes the energy balance of the structure at any instant $t$ under a horizontal ground motion. In this equation, $E_{I}$ is the (relative) [19] energy input by the earthquake; $W_{\xi}$ is the energy dissipated by the inherent damping mechanism; $W_{p}$ is the hysteretic (plastic strain) energy; $W_{e s}$ is the elastic strain energy; and $W_{k}$ is the kinetic energy. The sum of the kinetic and the elastic strain energies represents the elastic vibrational energy $W_{e}\left(=W_{e s}+W_{k}\right) . E_{I}$ and $W_{k}$ can be easily calculated by Eqs. (3) and (4) from the masses $m_{i}$, their relative displacements $u_{i}$, and the acceleration on the shake-table $\ddot{u}_{g}$ measured during the tests. $W_{p}$ and $W_{e s}$ can be estimated as explained in subsection 4.4 in the succeeding text. Further, according to Eq. (2), the difference $E_{I}-W_{e}=E_{I}-\left(W_{k}+W_{e s}\right)=W_{p}+W_{\xi}$ represents the total absorbed energy.

$$
\begin{gathered}
E_{I}=W_{\xi}+W_{p}+W_{e s}+W_{k} \\
E_{I}=\sum_{i=1}^{2} \int_{0}^{t} m_{i} \ddot{u}_{g} \dot{u}_{i} d t \\
W_{k}=\frac{1}{2} \sum_{i=1}^{2} m_{i} \dot{u}_{i}^{2} d t \\
W_{\xi}=\int_{0}^{t} \dot{\mathbf{u}}^{\mathbf{T}} \mathbf{C} \dot{\mathbf{u}} d t
\end{gathered}
$$

Figure 12 shows the histories of total input energy $E_{I}$ and total absorbed energy $W_{p}+W_{\xi}$ accumulated in the successive seismic simulations. It is seen in the figure that (i) $E_{I}$ and $W_{p}+W_{\xi}$ are almost coincident because the elastic vibrational energy is negligible and (ii) the amounts of $E_{I}$ in seismic simulations $\mathrm{C} 50$ and $\mathrm{C} 100$ are much smaller than in the rest of the simulations. A portion of the total absorbed energy $W_{p}+W_{\xi}$ is dissipated by viscous damping, $W_{\xi}$. In a shake-table test that goes deeply into the nonlinear range, it is hard to distinguish hysteretic from viscous damping. Thus, it is not possible to calculate $W_{\xi}$ with accuracy. An attempt was nonetheless made to obtain a rough estimation of $W_{\xi}$ as follows. First, the tested structure was idealized as a 2D model with two lumped masses. Second, the viscous damping of the structure was represented by the traditional Rayleigh damping matrix using the frequencies obtained for the first and second vibration modes from an eigenvalue analysis and adopting the same damping ratio $\xi$ for both modes. Third, the history of velocities of each mass was calculated by deriving the history of displacements measured

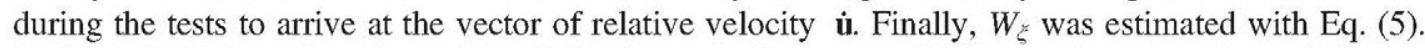
In this calculation, the value adopted for $\xi$ is very important. In this study, two values of $\xi$ were used. One is the damping ratio $\xi$ obtained from the free vibration test $(\xi=2.6 \%)$ conducted at the end of each seismic simulation. The second $(\xi=1.0 \%)$ is the value used in past studies that applied a similar approach for representing damping [20]. Martinelli and Filippou [20] predicted the

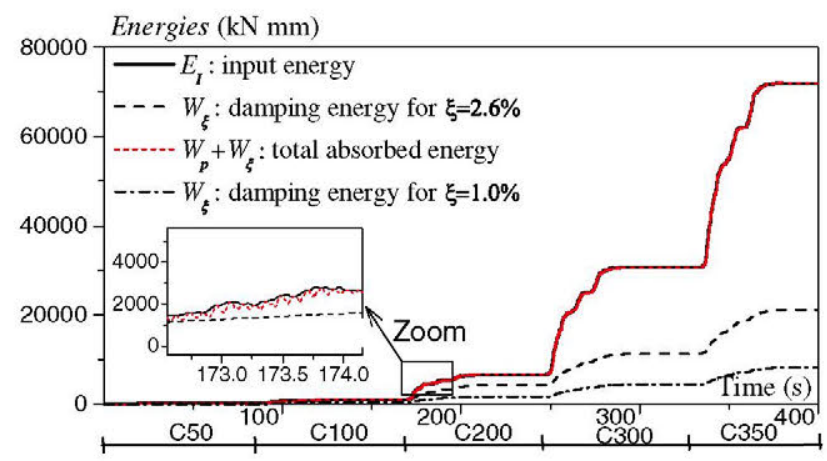

Figure 12. Histories of accumulated energy. 
nonlinear response of a full-scale seven-story RC structure tested on a shaking table under four successive input motions using a common damping ratio $\xi=1 \%$ for all seismic simulations and found that analytical results led to a good agreement between the measured and predicted response. The history of $W_{\xi}$ estimated with $\xi=2.6 \%$ and with $\xi=1.0 \%$ is shown in Figure 12 . In both cases, $W_{\xi}$ represents a relatively small amount of the total input energy $E_{I}$, ranging from one-sixth to onethird of $E_{I}$. Table III summarizes the energy input in each seismic simulation $j, E_{I, j}$ accumulated from the onset of the tests up to a given seismic simulation $s$, that is, $\sum_{j=1}^{s} E_{I, j}$, normalized to the total mass $\left(m_{1}+m_{2}\right)$ and expressed by an equivalent velocity $V_{E}$ given by

$$
V_{E}=\sqrt{2 \sum_{j=1}^{s} E_{I, j} /\left(m_{1}+m_{2}\right)}
$$

The difference $E_{I}-W_{\xi}$ is what Housner [21] called the energy that damages a structure subjected to seismic action and will be referred to as $E_{D}\left(=E_{I}-W_{\xi}\right)$ hereafter. Similarly to $V_{E}$, the amount of energy that damaged the test specimen in a given seismic simulation $j, E_{D, j}$. can be accumulated from the onset of the tests up to a given seismic simulation $s$ and converted into an equivalent velocity $V_{D}$ with an expression analogous to Eq. (6) just by replacing $E_{I, j}$ with $E_{D, j}$. This $V_{D}$ is a quantitative indicator of the damage imparted by the earthquake to the structure. Table III shows the $V_{D}$ estimated for $\xi=2.6 \%$ and for $\xi=1.0 \%$. Because the specimen was scaled by the factors indicated in subsection 2.3 , the values corresponding to $V_{E}$ and $V_{D}$ in the prototype structure, $V_{E, p}$ and $V_{D, p}$, can be calculated by $V_{E, p}=V_{E} / \lambda_{v}$ and $V_{D, p}=V_{D} / \lambda_{v}$, where $\lambda_{v}=\lambda_{L} / \lambda_{t}=0.63$ is the scaling factor for velocity.

\subsection{Damage at local level in the RC frame}

The elastic and plastic strain energy absorbed/dissipated by a given plastic hinge $k$ during the cyclic loading, $W_{e s, k}+W_{p, \mathrm{k}}$, is the sum of the energy dissipated by the longitudinal reinforcement, $W_{S, k}$ and the energy dissipated by the concrete, $W_{C, k}[22]$, that is, $\left(W_{e s, k}+W_{p, k}\right)=\left(W_{S, k}+W_{C, k}\right)$. The former, $W_{S, k}$, was estimated from the strains measured by the gages located at the longitudinal rebars, by using an energy conservative steel model that relates stress with strain and incorporates strain hardening and Bauschinger effects. The latter, $W_{C, k}$, was estimated from the curvature measured with the gages located on the steel rebars of the cross section, using the plane-remaining-plane assumption and the modified Kent and Park material model [23] for relating stress with strain at each fiber of the cross section. In the calculation of $W_{S, k}$ and $W_{C, k}$, it was assumed that the strains were constant along a plastic hinge length equal to the depth of the member. Further, $W_{p, k}$ can be estimated from $\left(W_{p, k}+W_{e s, k}\right)$ by removing from the latter the reversible elastic part. A detailed description of the procedure and equations to obtain $W_{S, k}$ and $W_{C, k}$ can be found in [22]. The total elastic/plastic strain energy absorbed/dissipated by the structure $W_{e s}+W_{p}$ is the sum of the contributions of the $p$ hinges, that is,

$$
W_{e s}+W_{p}=\sum_{k=1}^{p}\left(W_{e s, k}+W_{p, k}\right)
$$

\begin{tabular}{|c|c|c|c|c|c|c|}
\hline \multirow[b]{3}{*}{ Simulation: } & \multicolumn{3}{|c|}{ Test Specimen $(\mathrm{cm} / \mathrm{s})$} & \multicolumn{3}{|c|}{ Prototype $(\mathrm{cm} / \mathrm{s})$} \\
\hline & \multirow[t]{2}{*}{$V_{E}$} & \multicolumn{2}{|c|}{$V_{D}$} & \multirow[t]{2}{*}{$V_{E, p}$} & \multicolumn{2}{|c|}{$V_{D, p}$} \\
\hline & & $\xi=1 \%$ & $\xi=2.6 \%$ & & $\xi=1 \%$ & $\xi=2.6 \%$ \\
\hline C50 & 18 & 14 & 0 & 28 & 22 & 0 \\
\hline $\mathrm{C} 100$ & 40 & 31 & 0 & 64 & 49 & 0 \\
\hline $\mathrm{C} 200$ & 103 & 89 & 61 & 163 & 141 & 96 \\
\hline C300 & 222 & 206 & 176 & 351 & 325 & 278 \\
\hline C350 & 340 & 320 & 285 & 537 & 505 & 450 \\
\hline
\end{tabular}

Table III. Cumulative input energy. 
The energy absorbed/dissipated by the plastic hinges during each seismic simulation calculated as explained earlier was grouped and summed up as follows: energy absorbed/dissipated at the base of the columns (i.e., hinges number 10, 20, 30, and 40 in Figure 7), energy absorbed/dissipated at beam ends (i.e., hinges number 50, 51, 52, 60, 61, and 62 in Figure 7), energy absorbed/dissipated at the upper ends of the columns of the first story (hinges number 11, 21, 31, and 41 in Figure 7), and energy absorbed/dissipated at lower ends of the columns of the second story (hinges number 12, 22, 32, and 42 in Figure 7). The total energy absorbed/dissipated by the hinges of each group, accumulated for the successive seismic simulations, is plotted in Figure 13. The resulting energies absorbed/dissipated by the $\mathrm{RC}$ frame are negligible in comparison with those dissipated by the EDDs, as discussed later.

The damage at the level of each individual hinge $k$ can be expressed in terms of maximum chord rotation demand $\theta_{m}$ in relation to chord rotation at ultimate capacity $\theta_{u}$, that is, $\theta_{m} / \theta_{u}=\max \left\{\left|\theta_{m}{ }^{+} / \theta_{u}{ }^{+}\right|,\left|\theta_{m}{ }^{-}\right| \theta_{u}{ }^{-} \mid\right\}$, the energy-based index $D_{i}$ proposed by Darwin and Nmai [24], and the well-known index of damage $D I_{P A}$ developed by Park and Ang [25]. The chord rotation demand $\theta_{m}$ was estimated from the measurements provided by displacement transducers during the tests. Chord rotation capacities at ultimate $\theta_{u}$ were predicted using the equation recommended by Eurocode 8-Part 3 (Annex A) [26] based on the work by Fardis [27] and others, and supported by recent shake-table tests [28]. The damage index $D_{i}$ and the Park and Ang index of damage $D_{P A}$ at a given hinge $k$ were calculated by

$$
\begin{gathered}
D_{i}=\frac{W_{p, k}}{0.5\left(M_{y}^{+} \theta_{y}^{+}+\left|M_{y}^{-}\right|\left|\theta_{y}^{-}\right|\right)} \\
D_{P A}=0.5\left[\frac{\theta_{m}^{+}-\theta_{y}^{+}}{\theta_{u}^{+}-\theta_{y}^{+}}+\frac{\left|\theta_{m}^{-}\right|-\left|\theta_{y}^{-}\right|}{\left|\theta_{u}^{-}\right|-\left|\theta_{y}^{-}\right|}\right]+\beta \frac{W_{p, k}}{0.5\left(M_{y}^{+} \theta_{u}^{+}+\left|M_{y}^{-}\right|\left|\theta_{u}^{-}\right|\right)}
\end{gathered}
$$

The chord rotation at yielding $\theta_{y}$ was also predicted using the equation recommended by Eurocode 8-Part 3 (Annex A) [26]. The parameter $\beta$ was taken as $\beta=0.1$. The yielding moments under positive and negative bending, $M_{y}{ }^{+}$and $M_{y}{ }^{-}$, were estimated with the following expressions for beams:

$$
M_{y}=0.9 h A_{t} f_{y}
$$

and for columns, if $N_{\max }>N>\left(0.4 b h f_{c}\right)$

$$
M_{y}=\frac{\left(0.8 A_{t} f_{y} h+0.12 b h^{2} f_{c}\right)\left(N_{\max }-N\right)}{N_{\max }-\left(0.4 b h f_{c}\right)}
$$

if $\left(0.4 b h f_{c}\right)>N>0$

$$
M_{y}=\left(0.8 A_{t} f_{y} h\right)+0.5 N h\left\{1-\left[N /\left(b h f_{c}\right)\right]\right\}
$$

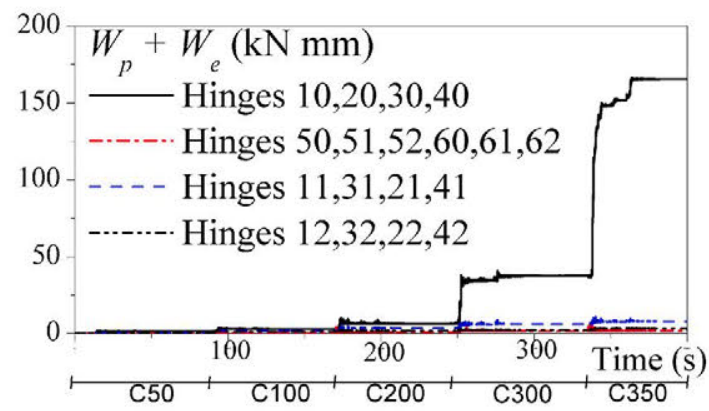

Figure 13. Energy absorbed/dissipated by the hinges of the RC frame. 
if $0>N>N_{\text {min }}$

$$
M_{y}=0.8 A_{4} f_{y} h+0.4 N h
$$

where $N$ is the axial force in the column (positive in compression); $N_{\max }=b h f_{c}+A_{g} f_{y} ; N_{\min }=-A_{g} f_{y} ; A_{t}$ is the area of longitudinal reinforcement in tension; $A_{g}$ is the total area of longitudinal reinforcement in the section; and $b, h$ are the base and depth of the section, respectively. The results are shown in Table IV. In the table, only the hinges at the base of the columns are shown because the damage in the rest of hinges was zero or extremely small (i.e., $\theta_{m} / \theta_{u} \leqslant 0.13 ; D_{i} \leqslant 0.09$; and $D I_{P A}=0$ ). It can be seen that the rotation demand on these hinges does not exceed one-fifth of their ultimate capacity, the energy dissipation demand in terms of index $D_{i}$ is below $10 \%$ of the energy dissipation capacity $\left(D_{i} \geqslant 35\right)$ of an RC member [24], and that the index $D I_{P A}$ is far from the value $\left(D I_{P A}=1\right)$ corresponding to the capacity of the member. In sum, the level of damage in the RC frame is very small.

\subsection{Damage in the EDDs}

The damage in hysteretic-type EDDs can be characterized by an index $\bar{I}$ proposed by Benavent-Climent [29]. The damage index $\overline{I D}$ measures the level between 0 (no damage) and 1 (failure). The accuracy of the damage model has been verified experimentally through dynamic real-time shake-table tests in the past research [29]. The calculation of index $\bar{D}$ involves decomposing the $N-\Delta$ curves shown in Figures 9, 10, and 11 into the so-called 'skeleton part' and 'Bauschinger part', and calculating the energy dissipated by each part, ${ }_{s} W_{u}^{+},{ }_{s} W_{u}^{-}$and ${ }_{B} W_{u}^{+},{ }_{B} W_{u}^{-}$, in the positive and negative domains of loading. The skeleton part is constructed for each domain of loading by connecting sequentially the segments of the $N-A$ curve that exceed the load level attained by the preceding cycle of deformation in the same domain of loading. The segments of the $N-\Delta$ curves that do not satisfy the earlier condition are classified as segments of the Bauschinger part. A more detailed explanation of this decomposition and the equations to obtain $\bar{D}$ can be found in references $[9,29]$. Table $\mathrm{V}$ shows the values of the damage index $\overline{I D}$ for each EDD (cumulative) up to the end of a given seismic simulation. It can be seen in the table that under the very frequent and frequent earthquakes (i.e., seismic simulations C50 and $\mathrm{C100}$ ), the EDDs remained basically undamaged. In subsequent seismic simulations, the level of damage became larger in the EDDs of the first story than in those of the second story. In the former, the EDDs exhausted about $15 \%$ of their ultimate capacity under the 'design earthquake' represented by seismic simulation $\mathrm{C} 200$, while they approached failure (having consumed about $80 \%$ of their ultimate capacity) after the very rare earthquakes represented by seismic simulations C300 and C350. In general, the EDDs played their expected role satisfactorily, that is, dissipating most of the energy input by the ground motions and preventing damage to the RC frame.

\subsection{Cost assessment}

Combining EDDs with RC frames can lead to structures with economic savings from both construction costs and repair costs after a severe earthquake. The cost of a main frame designed only for gravitational loads that is not required to develop a strong column-weak beam mechanism under lateral loads is lower than that of a conventional bare RC frame, which must be stringently detailed to attain ductility and follow capacity design principles. When low-cost hysteretic dampers such as the type discussed in this study are used, the cost of the dampers can be largely compensated with the savings in the cost of the main structure. A rough comparison between the prototype structure

Table IV. Rotation demand and damage indexes at the hinges of the RC frame.

\begin{tabular}{lcccccccccccccccc}
\hline Test: & \multicolumn{3}{c}{$\mathrm{C} 50$} & \multicolumn{4}{c}{$\mathrm{C} 100$} & \multicolumn{4}{c}{$\mathrm{C} 200$} & \multicolumn{4}{c}{$\mathrm{C} 300$} & \multicolumn{4}{c}{$\mathrm{C} 350$} \\
\hline Hinge & $\theta_{m} / \theta_{u}$ & $\mathrm{D}_{\mathrm{i}}$ & $\mathrm{DI}_{\mathrm{PA}}$ & $\theta_{m} / \theta_{u}$ & $\mathrm{D}_{\mathrm{i}}$ & $\mathrm{DI}_{\mathrm{PA}}$ & $\theta_{m} / \theta_{u}$ & $\mathrm{D}_{\mathrm{i}}$ & $\mathrm{DI}_{\mathrm{PA}}$ & $\theta_{m} / \theta_{u}$ & $\mathrm{D}_{\mathrm{i}}$ & $\mathrm{DI}_{\mathrm{PA}}$ & $\theta_{m} / \theta_{u}$ & $\mathrm{D}_{\mathrm{i}}$ & $\mathrm{DI}_{\mathrm{PA}}$ \\
\hline 10 & 0.02 & 0.01 & 0.00 & 0.04 & 0.02 & 0.00 & 0.09 & 0.05 & 0.00 & 0.15 & 0.22 & 0.05 & 0.20 & 1.10 & 0.19 \\
20 & 0.02 & 0.04 & 0.00 & 0.04 & 0.08 & 0.00 & 0.09 & 0.17 & 0.00 & 0.15 & 0.95 & 0.12 & 0.20 & 3.41 & 0.43 \\
30 & 0.02 & 0.02 & 0.00 & 0.04 & 0.06 & 0.00 & 0.09 & 0.21 & 0.00 & 0.15 & 0.61 & 0.09 & 0.20 & 1.04 & 0.19 \\
40 & 0.02 & 0.01 & 0.00 & 0.04 & 0.03 & 0.00 & 0.09 & 0.07 & 0.00 & 0.15 & 0.62 & 0.09 & 0.20 & 3.47 & 0.43 \\
\hline
\end{tabular}


Table V. Damage index $\overline{I D}$ in the EDDs.

\begin{tabular}{llllll}
\hline Damper & C50 & C100 & C200 & C300 & C350 \\
\hline D1 & 0.02 & 0.05 & 0.17 & 0.45 & 0.77 \\
D2 & 0.01 & 0.02 & 0.12 & 0.42 & 0.78 \\
D3 & 0.00 & 0.01 & 0.03 & 0.07 & 0.12 \\
D4 & 0.00 & 0.01 & 0.03 & 0.06 & 0.12 \\
\hline
\end{tabular}

with dampers investigated in this paper and a counterpart structure with conventional bare RC frames designed for the same seismic hazard [28] gives that the former requires approximately one-half of the volume of concrete and of the weight of reinforcing steel required by the latter. The reasons for this are as follows: (i) the former was designed only for gravity loads and the latter for both gravity and seismic loads; (ii) the conventional bare frame was designed to develop a strong column-weak beam mechanism while the frame with dampers was not; (iii) the frame with dampers was made intentionally flexible (by reducing the size of beams and columns) to enhance its lateral deformation capacity in the quasi-elastic range. Also, the increase in steel due to the addition of dampers in the former is largely compensated with the savings in reinforcing steel in the latter. In addition to the construction costs, the cost of repairing an RC frame with EDDs after a severe earthquake will most likely be zero because of the following: (i) the main frame remains basically elastic, as shown in subsections 4.2 and 4.4, and (ii) the EDDs do not need to be replaced after a single severe event, because the amount of dissipated energy is low in relation to their ultimate capacity, as shown in sub section 4.5. In contrast, severe damage is typically expected in a conventional bare RC frame after the design earthquake and the cost of repairing the structure may be very high.

\section{CONCLUSIONS}

Shake-table tests were conducted on a two-fifths-scale RC frame structure with hysteretic dampers. The $\mathrm{RC}$ frame was designed only for gravitational loads. Detailing requirements and prescriptions for the formation of a 'strong column-weak beam' mechanism under lateral loads as typically applied to conventional RC structures (without EDDs) in seismic zones were relieved. The hysteretic dampers installed in the RC frame provided a lateral strength and stiffness three and 12 times larger, respectively, than the corresponding values on the RC frame without EDDs. The specimen was subjected to five seismic simulations representative of very frequent, frequent, rare, and very rare earthquakes associated with return periods of $17,97,500,1435$, and 2032 years, respectively, in the Mediterranean area. The results of the tests lead us to put forth the following conclusions:

(1) The overall response of the system in terms of base shear versus top displacement curves was characterized by a stable energy dissipation behavior with minor pinching in the loops. The tested structure showed an overstrength of (1.6), which is about $25 \%$ larger than that specified by Eurocode-8.

(2) The RC frame remained basically elastic with light or very light damage, even for the severest seismic simulation. Strains in reinforcing rebars remained below the yield stain of the steel, except at the base of the columns, where they did not exceed 4.5 times the yield strain. At the base of the columns, the maximum rotation demand did not exceed $20 \%$ of the ultimate rotation capacity, and the average value of Park and Ang's index of damage was 0.3 , far from the value of 1 that corresponds to failure. The residual inter-story drifts were negligible $(\leqslant 0.1 \%)$, the fundamental period remained basically unchanged, and the concrete crack widths were kept below $0.2 \mathrm{~mm}$. Based on these facts, the structural performance level of the RC frame can be classified as 'Immediate Occupancy', although the maximum inter-story drift exceeded by $43 \%$ the maximum value $(1 \%)$ assigned to this performance level by ATC- 40 and FEMA356. This maximum inter-story drift of $1 \%$ is an average value derived on a statistical basis. The results of this study confirm that differences of about $40 \%$ are acceptable for relatively flexible RC frames, such as those designed only for gravitational loads. 
(3) The hysteretic dampers remained elastic for the very frequent and frequent earthquakes and suffered large plastic deformations under the rare and very rare ground motions. The dampers dissipated most of the energy input by the earthquake, while the plastic strain energy dissipated by the RC frame was negligible (less than $0.25 \%$ ). At the end of the last seismic simulation, the dampers of the first story approached their ultimate capacity.

(4) The requirements of ductility and developing a strong column-weak beam mechanism under lateral loads can be relieved in RC frames when they are combined with hysteretic dampers. The experimental results show that a mixed system ( $\mathrm{RC}$ frame + dampers) with a very satisfactory seismic performance (i.e., light damage to the main frame and most of the input energy dissipated by the dampers) can be attained if the RC frame is able to remain basically elastic and keep its integrity for inter-story drifts of about $1 \%$, and if its columns are able to dissipate a small amount of energy without failing in shear. The reinforcing detailing needed to comply with this desired performance corresponds to an 'ordinary moment frame' assigned to Structural Design Category B, according to ACI 318-08.

This research was supported by the Spanish Ministry of Science and Innovation under grant numbers BIA2008-00050 and BIA2011-26816 and the European Union (Fonds Européen de Dévelopment Régional). 